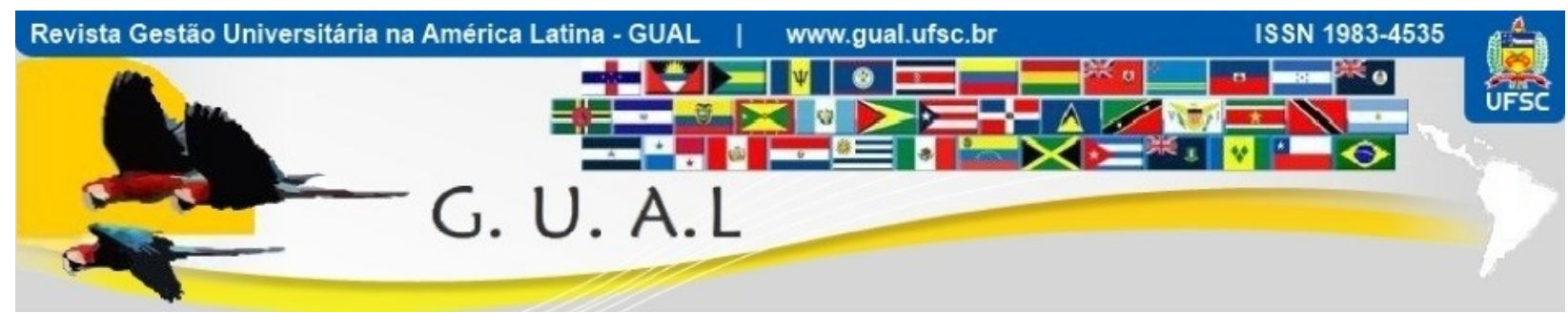

DOI: http://dx.doi.org/10.5007/1983-4535.2016v9n3p315

\title{
FATORES QUE AFETAM A GESTÃO DE CONTRATOS PSICOLÓGICOS NA UNIVERSIDADE FEDERAL DE SANTA CATARINA - UFSC
}

\author{
FACTORS THAT AFFECT THE MANAGEMENT OF PSYCHOLOGICAL \\ CONTRACTS IN THE UNIVERSIDADE FEDERAL DE SANTA CATARINA - UFSC
}

Alessandra de Linhares Jacobsen, Doutora
Universidade Federal de Santa Catarina - UFSC
alessandradelinharesjacobsen@gmail.com
Cláudio José Amante, Doutor
Universidade Federal de Santa Catarina - UFSC
claudiojosea@yahoo.com.br
Elaine Cristina de Lima, Mestre
Universidade Federal de Santa Catarina - UFSC
elaine.lima@ufsc.br

Recebido em 04/julho/2015

Aprovado em 29/julho/2016

Sistema de Avaliação: Double Blind Review

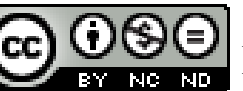

Esta obra está sob uma Licença Creative Commons Atribuição-Uso. 


\title{
RESUMO
}

Este artigo tem como objetivo analisar como se apresentam os fatores de influência dos contratos psicológicos no Centro de Filosofia e Ciências Humanas (CFH), da UFSC com vistas a apoiar a gestão neste tipo de Instituição. A metodologia usada concentra-se na pesquisa predominantemente qualitativa, descritiva, e estudo de caso. Como técnicas de coleta de dados, foram utilizadas a pesquisa bibliográfica, a pesquisa documental e o questionário aplicado aos sujeitos selecionados, de modo não probabilístico, por acessibilidade e por tipicidade. $\mathrm{O}$ questionário foi formado por questões fechadas do tipo múltipla escolha e em escala Likert. Os dados coletados foram analisados estatisticamente a partir de análise interpretativa. Como resultados, foram levantados como se apresentam fatores de influência dos contratos psicológicos, e apontados os de maior influência, bem como foram propostas sugestões para corrigir falhas identificadas pela pesquisa. Concluiu-se que os fatores de maior influência são favoráveis para contratos psicológicos em equilíbrio, porém há outros a serem melhorados. Como principais alternativas de ação, sugerem-se conscientização sobre a importância da análise dos contratos psicológicos, comunicação clara e constante desde o ingresso na Instituição e a formação de Comissão para gerir os referidos contratos.

Palavras-Chave: Gestão Universitária. Contratos psicológicos. Gestão de contratos psicológicos.

\begin{abstract}
This article aims to analyze the influence of the psychological contracts factors in the Philosophy and Human Sciences Centre (CFH/UFSC) in order to support the management in this kind of institution. The methodology was predominantly qualitative, descriptive and case study. Data collection techniques used were the bibliographical research, documentary research and the questionnaire administered to selected subjects, not probabilistic, considering accessibility and typicality. The questionnaire consisted of closed questions multiple-choice and Likert scale. Data were statistically analyzed by interpretative analysis. The results presented the most influential psychological contracts factors and some suggestions were given to correct deficiencies identified by the survey. It was concluded that the most influential factors are favorable for psychological contracts in balance, but there are others to be improved. It is suggested to be aware of the importance of psychological contracts, clear and constant communication since the beginning and committee formation to manage such contracts.
\end{abstract}

Keywords: Higher education management. Psychological contracts. Psychological contracts management. 


\section{INTRODUÇÃO}

Estudos organizacionais mostraram que, em se tendo o indivíduo um ser não controlável e imprevisível, sempre há um grau de incerteza associado à gestão de pessoas (MOTTA; VASCONCELOS, 2008). No constructo contrato psicológico, esta perspectiva é considerada já que fazem parte indivíduo e organização, ambos com suas expectativas, que são criadas a partir de suas necessidades, daquilo que aprenderam dos outros, de tradições e normas, de suas experiências passadas e de diversas outras fontes (SCHEIN, 1982). Schein (1982) destaca que, quando as necessidades e as forças externas mudam, também as expectativas mudam, o que significa dizer que os contratos psicológicos são dinâmicos. E, sendo assim, devem ser renegociados constantemente, pois, embora não sejam explícitos, nem escritos, são de grande influência no comportamento das organizações.

Tais prerrogativas provocam o estudo crescente do tema, pois, como apontam Correia e Mainardes (2010), os resultados organizacionais estão associados ao cumprimento do contrato psicológico, tais como empenhamento, satisfação, comportamentos de cidadania organizacional, intenção de sair ou ficar na organização. Da mesma forma, também consequências negativas à organização vêm sendo associadas à violação dos contratos psicológicos, como diminuição do empenhamento e da cidadania organizacionais e aumento do absenteísmo.

Em outras palavras, de acordo com Rousseau (1989), no ambiente organizacional, a percepção pelo indivíduo de que suas expectativas estão, ou não, sendo atendidas, faz com que ele retribua em conformidade com esta percepção.

No que se refere às universidades federais, ambiente de estudo desta pesquisa, o cenário apresenta ainda maiores desafios de gestão, visto que, além dos parâmetros já citados sobre organizações públicas, uma universidade, diante do papel que representa, deve atender necessidades e exigências do público externo, da sociedade em que está inserida e, ao mesmo tempo, lidar com dificuldades internas, tais como possuir múltiplas tarefas, além das atividades fins de ensino, pesquisa e extensão, o que exige uma organização diferenciada. Além disso, possui múltiplos objetivos, muitas vezes conflitantes entre os diversos setores, cada um com seus próprios interesses e valores, e, devido à complexidade de sua natureza, as universidades costumam ter estruturas grandes, o que gera ainda maior dificuldade de coordenação e comunicação (SOUZA, 2009). 
A Universidade Federal de Santa Catarina (UFSC 2016a), ambiente onde se desenvolve o presente estudo, é uma Instituição Federal de Ensino Superior (IFES) que apresenta mais de 50 anos de existência, atende mais de 35.000 estudantes, desde o ensino infantil até a pós- graduação, conta com mais de 3.000 servidores Técnicos-Administrativos em Educação (TAEs) e mais de 2.000 servidores docentes (1). Entre os centros de ensino da UFSC há o Centro de Filosofia e Ciência Humanas (CHF), que apresenta certas particularidades.

O CFH oferece nove cursos regulares de graduação: Antropologia, Ciências Sociais, Filosofia, Geografia, Geologia, História, Museologia, Oceanografia e Psicologia e um curso em caráter experimental, o de Licenciatura Intercultural Indígena do Sul da Mata Atlântica. Este Centro possui mais de 2300 alunos e 150 professores que se dedicam, além das atividades de ensino nos âmbitos da graduação e pós-graduação, a projetos de pesquisa e de extensão, coordenando e participando de grupos de pesquisa cadastrados pelo CNPq. Entre os diversos departamentos do CFH e o Museu de Arquiologia e Etnologia, trabalham um total de 80 TAEs (UFSC, 2016b). Destes 80 TAEs, existe um recorte de 28 TAEs, que são os sujeitos desta pesquisa, por fazerem parte de um montante de novos servidores, contratados a partir de 2008, ano em que depois de um longo período a Instituição voltou a fazer novos processos seletivos. Estes novos servidores foram escolhidos como alvo desta investigação visto que tentativas de melhorar seus contratos psicológicos podem ser mais bem sucedidas, pois, segundo Coyle-Shapiro e Parzefall (2005), a adaptação deste tipo de contrato é mais provável durante a sua formação. Durante as primeiras fases da relação de trabalho, influências organizacionais são mais fortes, e as diferenças entre as expectativas do indivíduo e da Instituição ainda podem ser reduzidas, enquanto que os contratos psicológicos mais antigos na organização são mais difíceis de serem ajustados por manterem-se mais estáveis. A PróReitoria responsável pela gestão de pessoas na UFSC é a PRODEGESP.

Diante da temática de investigação e do contexto apresentado, surge o seguinte objetivo de pesquisa: Analisar como se apresentam fatores de influência dos contratos psicológicos estabelecidos entre a Instituição e os servidores Técnico-Administrativos em Educação (TAEs) do Centro de Filosofia e Ciências Humanas (CFH), e como podem ser geridos?

Portanto, são várias as justificativas para este estudo, visto que, para atender às exigências presentes nas Instituições de ensino, no contexto do mundo contemporâneo, seja 
por parte do seu público externo, de órgãos de fomento, de estudantes, de instituições conveniadas, e de seus trabalhadores, tais instituições precisam estar preparadas, e contar com seu corpo técnico-funcional comprometido, produtivo e satisfeito com o trabalho que realizam, com suas funções, com seu ambiente e com sua equipe de trabalho. Para tanto, é necessária uma atitude diagnóstica e flexível que perceba os acontecimentos e a interpretação deles pelas pessoas que participam de determinada situação e, assim, se escolha um esquema de ação apropriado para cada uma (SCHEIN, 1982). Neste contexto, entender o contrato psicológico possibilita uma melhor compreensão das pessoas, seus inter-relacionamentos, seus sentimentos de satisfação e consequentes comportamentos (GONDIM; SILVA, 2004).

Ainda segundo pesquisa realizada por Rios e Gondim (2010), a produção acadêmica em relação aos contratos psicológicos no Brasil é recente e escassa, o que justifica estudar o fenômeno, com vistas a ampliar o conhecimento cintífico sobre o tema.

Em termos práticos, observam-se os contratos psicológicos como meio para o desenvolvimento, na UFSC, de uma política participativa e uma comunicação clara para que esses contratos não sejam violados ou abandonados, gerando baixos níveis de compromisso e de resultados. Dizem Rios e Gondim (2010) que estudos sobre estas expectativas recíprocas poderiam contribuir para processos motivacionais e de liderança e, inclusive, o planejamento estratégico poderia ser melhorado levando-se em conta as expectativas daqueles envolvidos direta ou indiretamente com as metas. Diante desta perspectiva, há aqui o interesse em contribuir, sugerindo-se ações para gerir os contratos psicológicos dos TécnicoAdministrativos em Educação de um Centro de Ensino da UFSC, onde se pretende ajustar as expectativas geradas continuamente entre os indivíduos que ali trabalham e as expectativas do próprio Centro, favorecendo a satisfação das pessoas, minimizando os malefícios gerados com a ruptura ou violação dos contratos psicológicos e maximizando os benefícios oriundos deles.

\section{FUNDAMENTAÇÃO TEÓRICA}

Inicialmente, este capítulo aborda sobre a gestão de pessoas em Instituições Federais de Ensino Superior - IFES, e, após, alguns aspectos sobre contratos psicológicos, finalizando com o que foi encontrado na literatura sobre a gestão dos contratos psicológicos.

\subsection{GESTÃO DE PESSOAS EM IFES}

Para que desempenhe seu papel estratégico, a gestão de pessoas, segundo Schikmann (2010), precisa conhecer sua organização de modo a alocar da melhor maneira possível seus 
trabalhadores, conhecendo o perfil deles e coordenando os seus esforços para suprir adequadamente as necessidades de pessoal e o alcance dos resultados organizacionais. Isto implica em um novo "contrato de trabalho" que, para Schikmann (2010, p. 25), não se trata de um contrato formal obrigatório para a efetivação de um funcionário, mas de um "contrato operacional e psicológico", onde são combinadas as formas de relacionamento entre as pessoas e a organização. Objetiva-se, daí, fazer com que o indivíduo se sinta mais comprometido e motivado para o trabalho.

De fato, não há uma forma que seja a única correta para se compreender o que motiva as pessoas e o que influencia em seus comportamentos, ao contrário, é preciso "adotar uma atitude diagnóstica e flexível, sensível aos acontecimentos e à interpretação deles por parte das pessoas que participam de determinada situação”. Após esta atitude diagnóstica, a escolha da ação estratégica mais coerente voltada à gestão de pessoas será mais facilmente acertada (SCHEIN, 1982, p. 30).

Concomitantemente, Fochesatto (2002) lembra que a carência de necessidades não supridas gera um estado de desequilíbrio e sensações emocionalmente negativas de ameaça à integridade do indivíduo. Quando as pessoas pretendem se livrar de tal sensação de desequilíbrio, associam expectativas à crença de que diferentes ações poderão conduzi-las a estados mais confortáveis. Por isso a necessidade de atenção às expectativas das pessoas, para que continuem na organização, desenvolvendo suas funções satisfatoriamente.

Nas universidades públicas, contudo, o alcance da motivação e comprometimento dos seus servidores precisa observar as particularidades deste tipo de instituição, afinal nelas há uma variedade de objetivos, cuja mensurabilidade é extremamente limitada, elas são formadas, basicamente, por um conjunto de pessoas em que as relações sociais e interpessoais extrapolam as estruturas prescritas no modelo racional burocrático, sua multidisciplinaridade, sua gestão de recursos intelectuais, geração e disseminação de conhecimento, propagação de debates, enfim, seus objetivos são extensos e complexos, localizando-se, neste contexto, o desafio em geri-lo (SOUZA, 2009).

Contudo, para que as expectativas dos servidores sejam atendidas igualmente como as da organização e, assim, tenha-se uma situação de equilíbrio, garantindo uma relação de trabalho vantajosa para ambas as partes, há de levar em conta aspectos relativos ao contrato psicológico firmado entre eles. Com vistas à compreensão deste construto, abordam-se a seguir, os contratos psicológicos. 


\subsection{CONTRATOS PSICOLÓGICOS}

Por "contrato" entende-se, em um sentido amplo, "qualquer crença num conjunto de obrigações que existem entre pelo menos duas partes, sendo uma obrigação caracterizada por um empenhamento em agir de uma certa maneira no futuro" (CAMPOY; CASTAING; GUERREIRO, 2005, p. 142). Em linhas gerais, entende-se que o contrato representa uma troca de promessas. Porém, neste contexto, vale ressaltar que uma obrigação só existe quando há livre aceitação de que, de uma forma ou de outra, a pessoa concorda com a condição de ficar obrigada.

O contrato de trabalho, afirmam Correia e Mainardes (2010), é composto por um contrato formal, que é aquele contrato escrito, e um contrato informal e implícito, denominado contrato psicológico. Ambos envolvem direitos, obrigações e expectativas por parte do indivíduo e da organização para a qual trabalha. Já para Chambel (2013), trata-se da percepção de cada indivíduo sobre um acordo de promessas mútuas em uma relação, independentemente do fato de existir formalmente esse acordo, e é essa percepção que irá influenciar as contribuições do indivíduo nessa relação.

Desde o momento em que um indivíduo é admitido em uma organização, já começa a ser estabelecido um vínculo não somente empregatício, mas, também, de expectativas econômicas e socioemocionais. Assim, é efetivado seu contrato psicológico, processo que perdura no seu dia-a-dia, quando ele vivencia sentimentos e relacionamentos. Por outro lado, a organização também elabora suas expectativas sobre o indivíduo, e, deste modo, as necessidades da organização também corresponderão a expectativas, estabelecendo-se um contrato psicológico quando as expectativas individuais e organizacionais se influenciam mutuamente, formando um relacionamento dinâmico, mutável, e que, constantemente, requer renegociação. Tudo isso sendo promovido por fatores individuais e ambientais. É uma ação humanizada exercida em um contexto social, com influências de distintas fontes, resultando em uma reciprocidade entre trabalhador e suas formas de relação com a organização social (MIGLIORINI, 2005).

França e Rodrigues (2011) também confirmam que o contrato psicológico é formado por expectativas. "Trata-se de um conjunto de expectativas que se estabelecem com interesses comuns" (FRANÇA; RODRIGUES, 2011, p. 140).

França e Rodrigues (2011) ressaltam ainda que, nesse jogo de interesses, a organização, em sentido amplo, é a que contrata a pessoa, mas em seu sentido restrito, são as 
pessoas ocupantes de cargos-chave, como as que realizam o recrutamento, a seleção, o treinamento, e, também, o departamento de pessoal, a chefia imediata e todos os que decidem, avaliam e estimulam, em nome da empresa, o comportamento do empregado.

Segundo comentam Coyle-Shapiro e Parzefall (2005), a origem da teoria do contrato psicológico teve início em duas teorias - a teoria da troca social e a teoria da norma de reciprocidade. Quanto à teoria de troca social, Blau (1964), apresenta dois tipos de relações: a troca econômica e a troca social.

Siqueira e Gomide Júnior (2004) diferenciam estes dois tipos de troca, afirmando que, na troca econômica, uma simples violação do contrato pode ser identificada, porém, na troca social, devido à ausência de regras explícitas, fica aberta a possibilidade de cada parte avaliar livremente os benefícios e/ou prejuízos oriundos deste tipo de relação.

Já, na teoria da norma de reciprocidade, segundo Coyle-Shapiro e Parzefall (2005), o contrato está no centro da troca social e pode corresponder à permuta de conteúdos idênticos, ou diferentes, mas de valor equivalente. Portanto as contribuições dos empregados ocorrem em função do que o empregador proporciona - satisfação ou ruptura do contrato -, ou seja, quanto maior a percepção de que as obrigações estão sendo cumpridas, mais importantes serão os esforços de reciprocidade realizados pelos empregados. Neste contexto, há casos em que estes últimos podem agir de maneira proativa, antecipando as obrigações que poderão ser cumpridas no futuro, ou empenham-se em uma relação recíproca com a intenção de serem, proximamente, atribuídas recompensas futuras. Estudos empíricos sugerem que esta norma de reciprocidade é o que constitui a base para o desenvolvimento e para a conclusão na relação de troca entre as partes (COYLE-SHAPIRO; PARZEFALL, 2005).

No entanto, os artigos de Rousseau, a partir de 1989, sofreram considerável mudança ao trazer a definição de contratos psicológicos como crença de um indivíduo em um acordo de troca recíproca entre duas partes em que são realizadas promessas e oferecidas compensações que ligam as partes a um conjunto de obrigações recíprocas (COYLE-SHAPIRO; PARZEFALL, 2005). Esta definição contrasta com as definições iniciais, à medida que Rousseau (1989) traz um conceito mais ao nível do indivíduo, além de realçar as obrigações em lugar das expectativas.

Embora tenha sido bastante aceita por investigadores, Coyle-Shapiro e Parzefall (2005) afirmam que a definição de Rousseau (1989) não é universal, uma vez que se verificam autores e concepções mais atuais, como as de Herriot e Pemberton (1997, p. 45), 
para os quais contrato psicológico é compreendido como "as percepções que as duas partes da relação de emprego, o indivíduo e a organização, tem de obrigações ligadas a essa relação", e trazem uma perspectiva relacional e não individual. Há, também, outras definições, como as de Schein (1982) e França e Rodrigues (2011), que consideram o contrato psicológico ser formado por expectativas, também implícitas.

Robinson e Rousseau (1994) definem contratos psicológicos como percepções individuais considerando termos e condições de um acordo de trocas recíprocas entre o indivíduo e outra parte. O contrato psicológico surge quando uma parte acredita que uma promessa de retorno futuro foi feita (por exemplo, uma remuneração por perfomance).

Dulac (2005) ainda afirma que o contrato psicológico se assenta, inclusive, de suas experiências tanto passadas como presentes, e também afirma que interações e trocas de informações com agentes organizacionais (colegas de trabalho, supervisores, líderes) influenciam a maneira como as pessoas percebem e interpretam o ambiente de trabalho e sua relação de emprego, (re)avaliam suas expectativas, suas crenças e seus pressupostos, e consequentemente, mudam e aperfeiçoam seu contrato psicológico antecipatório. A percepção de injustiça na relação de trocas segundo Dulac (2005), afeta o processo de interpretação dos indivíduos que, se não for bem explicada pode trazer reações negativas e sentimentos de violação de contrato psicológico.

O esquema mental, ainda segundo Dulac (2005), vai se ajustando progressivamente, até que haja um preenchimento suficiente de informações que satisfaça o indivíduo e se forme uma consistência entre as experiências organizacionais e as crenças individuais. Ou seja, depois de formado, o contrato psicológico passa a ser confrontado com experiências organizacionais diversas, sendo que, nesse momento, se o contrato psicológico do indivíduo é razoavelmente consistente à realidade da organização, ele se constitui em um contrato resistente a mudanças, embora possa ser objeto de revisões e adaptações baseadas nas experiências vividas por tal indivíduo (DULAC, 2005).

Vale assinalar,ainda, que, segundo conferem Coyle-Shapiro e Parzefall (2005), há estudos que sugerem estar o contrato psicológico mais sujeito a mudanças em seu período de formação. Entre os empregados mais antigos, os esquemas são estáveis e suscitam uma impressão de ordem, estrutura e coerência de estímulos sociais. Por outro lado, os esquemas dos mais novos são mais complexos, imprevisíveis e, muitas vezes, mais difíceis de suportar (COYLE-SHAPIRO; PARZEFALL, 2005). 
Torna-se importante, então, conhecer os fatores que podem influenciar nos contratos psicológicos, por esta razão, apresenta-se na próxima seção conteúdo pesquisado na literatura sobre o assunto.

\subsubsection{Fatores que influenciam os contratos psicológicos}

Na concepção de Davidson (2002), há dois componentes que afetam a natureza dos contratos psicológicos e que, por isso, precisam ser cuidadosamente observados. São eles:

a) O conteúdo: refere-se ao que é possível de ser negociado, como, por exemplo, os benefícios e o nível de esforço exigido. Os fatores do componente conteúdo podem ser tangíveis (como o salário), ou intangíveis (como o tratamento justo);e,

b) O processo, em contrapartida, diz respeito a como será o contrato, ou a relação entre organização e indivíduo. Qualquer processo organizacional que afete o indivíduo deve fazer parte de seu contrato psicológico.

Os fatores que constituem os componentes Conteúdo e Processo estão ilustrados por meio da Figura 01 e da Figura 02, ambas dispostas a seguir.

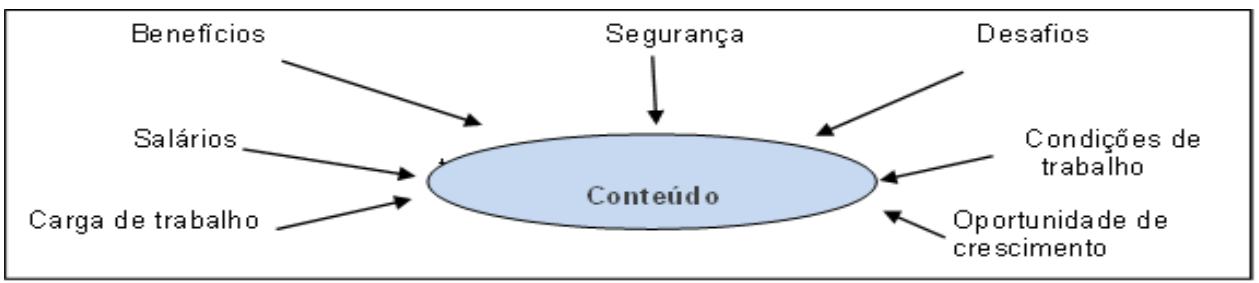

Figura 1 Fatores relacionados ao conteúdo. Fonte: Adaptado de Davidson (2002).

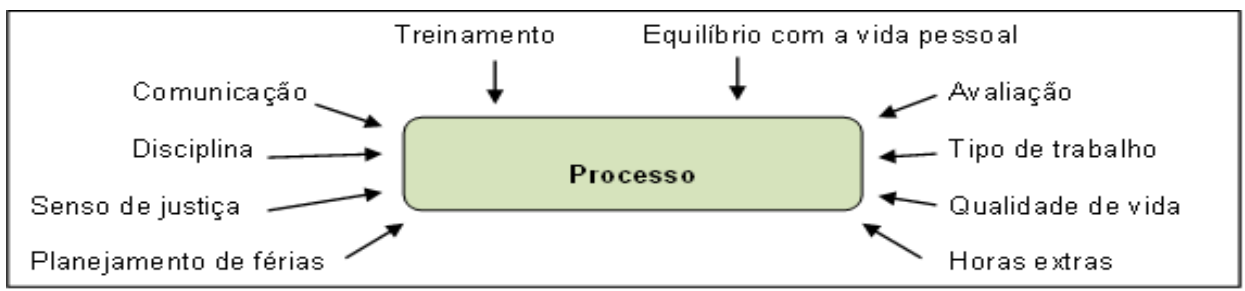

Figura 02 Fatores relacionados ao processo. Fonte: Adaptado de Davidson (2002).

Além destes fatores, Davidson (2002), em sua pesquisa sobre contrato psicológico, identificou outros seis elementos-chave principais que compõem o fenômeno, que são:

a) O equilíbrio entre os benefícios gerados pelo empregado e as recompensas esperadas;

b) A quantidade de escolhas percebidas no momento;

c) $\mathrm{O}$ ritmo de mudanças experimentadas;

d) A importância percebida de confiança no contrato; 


\section{FATORES QUE AFETAM A GESTÃO DE CONTRATOS PSICOLÓGICOS NA UNIVERSIDADE

e) O nível de clareza existente; e,

f) A extensão em que o contrato foi individualizado.

Partindo da perspectiva de Campoy, Castaing e Guerreiro (2005), verifica-se que as obrigações que constituem uma relação de trabalho, tanto são das organizações para com o empregado, quanto dos empregados para com a organização. Desta forma, os autores apresentam dois quadros que relacionam estas obrigações, porém, para o presente artigo, estes quadros foram adaptados, optando-se por aquelas que estão mais relacionadas às de um contrato psicológico, não contemplando as que costumam ser apresentadas em contratos formais de trabalho e em regulamentações. Adicionalmente, a seleção feita está alinhada com a realidade brasileira, pois os quadros originais são baseados na realidade de onde a obra foi escrita, Portugal. O conjunto selecionado de obrigações está ilustrado nos Quadro 01 e no Quadro 02, desenhados a seguir.

\begin{tabular}{||l||l||}
\hline \hline Remuneração ligada a performances & Envolvimento nas decisões \\
\hline \hline $\begin{array}{l}\text { Coerência do sistema de remuneração dentro } \\
\text { da organização }\end{array}$ & Integridade/honestidade \\
\hline \hline Estímulo à formação e capacitação & Recursos para poder trabalhar bem \\
\hline \hline Possibilidade de desenvolvimento pessoal & Carga de trabalho não excessiva \\
\hline \hline $\begin{array}{l}\text { Possibilidades de desenvolvimento } \\
\text { profissional }\end{array}$ & Segurança no trabalho \\
\hline Apoio para fazer carreira & Ser tratado de maneira justa e equitativa \\
\hline \hline Reconhecimento de performance & Explicitações das regras \\
\hline \hline Apoio e respeito perante problemas pessoais & Boa comunicação e cooperação entre colegas de trabalho \\
\hline \hline Autonomia no trabalho & Bom ambiente de trabalho \\
\hline \hline Ter responsabilidades & Equilibrio entre vida pessoal e profissional \\
\hline Desafios no trabalho & Boa comunicação com superiores hierárquicos \\
\hline \hline Autonomia para tomar decisões & $\begin{array}{l}\text { Consulta e comunicação nos assuntos que tangem aos } \\
\text { empregados }\end{array}$ \\
\hline \hline Utilização de competências & $\begin{array}{l}\text { Possibilidade de horários flexíveis compatíveis com } \\
\text { necessidades pessoais }\end{array}$ \\
\hline
\end{tabular}

Quadro 01 Obrigações da organização em relação ao empregado. Fonte: Adaptado de Campoy, Castaing e Guerreiro (2005).

\begin{tabular}{|l|l||}
\hline \hline Adaptar-se às mudanças & Ser honesto e ético profissionalmente \\
\hline \hline Aceitar mudança de função & Proteção das informaços da empresa \\
\hline \hline Desenvolver novas competências & Utilizar honestamente os recursos da empresa \\
\hline \hline Seguir formações fora das horas de trabalho & Querer permanecer na empresa \\
\hline \hline $\begin{array}{l}\text { Estar informado das possibilidades de } \\
\text { desenvolvimento na profissão e na empresa }\end{array}$ & Respeitar procedimentos e políticas organizacionais \\
\hline \hline Vestir-se e comportar-se corretamente & Ser digno de confiança \\
\hline \hline $\begin{array}{l}\text { Aceitar, se necessário, tarefas além das } \\
\text { atribuições }\end{array}$ & Melhorar os métodos de trabalho \\
\hline \hline Aceitar horários flexíveis & Pôr em primeiro lugar os interesses da organização \\
\hline \hline Cumprir horários previstos contratualmente & Ser fiel à empresa \\
\hline
\end{tabular}




\begin{tabular}{|l|l|}
\hline Ter boas relações com os colegas & Trabalhar eficazmente \\
\hline \hline Cooperar com os colegas & Fornecer um trabalho suficiente e de qualidade \\
\hline
\end{tabular}

Quadro 02 Obrigações do empregado em relação à organização.

Fonte: Adaptado de Campoy, Castaing e Guerreiro (2005).

Há, também, sobre o tema desta pesquisa, um artigo de Maia e Bittencourt (2014), no qual os autores oferecem um Instrumento de Avaliação de Contrato Psicológico (ICP) projetado e, devidamente validado, em uma organização pública federal brasileira. Segundo estes autores, a decisão de construir o ICP decorre de se ter constatada a inexistência de um instrumento de investigação dos contratos psicológicos voltado especificamente à realidade do Brasil e adaptado à língua portuguesa. Diante deste cenário Maia e Bittencourt (2014), por meio da adoção de técnicas quantitativas e qualitativas, acabam por construir e proceder a validação psicométrica do ICP, que assume um aspecto bilateral do contrato psicológico, abrangendo crenças do empregado, tanto de suas obrigações para com a organização, quanto as obrigações do empregador para com os empregados.

O estudo resultou em um ICP validado com três dimensões (MAIA; BITTENCOURT, 2014), a saber:

a) Tangibilidade - reúne itens referentes ao grau em que o empregado percebe os termos do contrato como definidos, sem ambiguidade e menos sujeitos a interferências externas e fora de controle, ou seja, o nível de objetividade dos termos do contrato. $\mathrm{O}$ empregado oferece abertura, participação e transparência. $\mathrm{O}$ empregador, por sua vez, oferece a noção de que ele é parte da organização, com papel bem definido, com transparência e clareza nas oportunidades, atribuições, recompensas, critérios de avaliação, reduzindo ambiguidades;

b) Foco - reúne itens relacionados aos itens em que o empregado percebe e racionaliza as diferenças entre o que investiu e o que obteve de retorno, e também entre ele e seus colegas de trabalho nas trocas mensuráveis; e,

c) Escopo - reúne itens que se referem ao grau-limite em que os objetivos organizacionais e as relações de trabalho influenciam a expressão intelectual e pessoal do indivíduo e vice-versa. Nesta dimensão, o empregado investe na organização e excede seu papel em consideração às necessidades organizacionais, e o empregador trata o empregado como pessoa, considerando suas características e necessidades pessoais. A seguir, apresenta-se, o Quadro 04 - Instrumento de Contrato Psicológico (ICP) validado em organização pública federal brasileira.

\begin{tabular}{|c|l|l|}
\hline Dimensão & \multicolumn{1}{|c|}{ Obrigações do empregador } & \multicolumn{1}{c|}{ Obrigações do empregado } \\
\hline \multirow{5}{*}{ Tangibilidade } & $\begin{array}{l}\text { descreva sem ambiguidade o que é } \\
\text { esperado de mim }\end{array}$ & $\begin{array}{l}\text { indique explicitamente meus desejos e } \\
\text { planos de carreira }\end{array}$ \\
\hline $\begin{array}{l}\text { descreva especificamente o critério de } \\
\text { avaliação de desempenho adotado }\end{array}$ & $\begin{array}{l}\text { estabeleça com clareza o que é importante } \\
\text { para mim no meu trabalho }\end{array}$ \\
\hline $\begin{array}{l}\text { cumpra rigorosamente o que for } \\
\text { comprometa-me com a organização por um }\end{array}$ \\
\hline
\end{tabular}




\begin{tabular}{|c|c|}
\hline & previamente acordado \\
\hline & $\begin{array}{l}\text { ofereça a orientação legal e técnica } \\
\text { necessária para que eu desenvolva o } \\
\text { trabalho }\end{array}$ \\
\hline & forneça-me feedback \\
\hline & $\begin{array}{l}\text { coloque os empregados em locais } \\
\text { compatíveis com suas características } \\
\text { profissionais }\end{array}$ \\
\hline \multirow{6}{*}{ Foco } & remunere-me satisfatoriamente \\
\hline & $\begin{array}{l}\text { determine prazos realistas para a entrega } \\
\text { de trabalhos }\end{array}$ \\
\hline & $\begin{array}{l}\text { não me submeta a uma carga excessiva de } \\
\text { trabalho }\end{array}$ \\
\hline & $\begin{array}{l}\text { não sobrecarregue de trabalho os melhores } \\
\text { funcionários }\end{array}$ \\
\hline & $\begin{array}{l}\text { não subutilize minha capacidade de } \\
\text { trabalho }\end{array}$ \\
\hline & $\begin{array}{l}\text { disponibilize materiais e equipamentos } \\
\text { adequados }\end{array}$ \\
\hline \multirow{6}{*}{ Escopo } & $\begin{array}{l}\text { trate-me como uma pessoa, não como um } \\
\text { número }\end{array}$ \\
\hline & $\begin{array}{l}\text { permita-me ser eu mesmo dentro da } \\
\text { organização }\end{array}$ \\
\hline & $\begin{array}{l}\text { dê-me autonomia para realizar meu } \\
\text { trabalho }\end{array}$ \\
\hline & $\begin{array}{l}\text { ofereça-me um trabalho que requeira } \\
\text { originalidade e criatividade }\end{array}$ \\
\hline & leve em conta minhas opiniões \\
\hline & Iç \\
\hline
\end{tabular}

longo tempo

traga ideias próprias e criatividade para melhoria das atividades

queira me desenvolver na organização

ajuste-me facilmente às mudanças na situação do trabalho

trabalhe ativamente enquanto estiver no local de trabalho

esforce-me no cumprimento dos objetivos pré-estabelecidos

apresente um volume de trabalho adequado, levando-se em conta as condições e complexidade de minhas atividades coopere com a equipe na realização dos trabalhos

desenvolva as minhas atividades com a qualidade requerida

zele por valores, bens e equipamentos institucionais sob minha guarda ou uso

preocupe-me com a organização, mesmo fora do horário de trabalho

trabalhe horas além do expediente quando necessário

lide bem com os imprevistos nas situações de trabalho aceite uma transferência para uma função diferente dentro da organização se necessário

Quadro 03 Instrumento de Contrato Psicológico (ICP) validado em organização pública federal brasileira. Fonte: Adaptado de Maia e Bittencourt (2014).

De acordo com Chambel (2013), embora a essência do contrato psicológico consista na percepção sobre as obrigações mútuas, está igualmente relacionada à percepção do quanto estão ou não sendo cumpridas e, a partir do momento em que uma das partes percebe que a outra não está cumprindo suas promessas, haverá um desequilíbrio na relação.

Contudo, de acordo com Dulac (2005), devido à grande incidência de percepção de desequilíbrio nos ambientes organizacionais, que desencadeiam rupturas, ou violações dos contratos psicológicos, torna-se evidente a necessidade de estudos e atenção de gestores sobre o assunto, visto que as percepções de brechas ou de violação provocam tensões e conflitos que podem repercutir nas atitudes e comportamentos dos empregados. Sendo assim, é fundamental compreender os fatores, as variáveis e os mecanismos que influenciam nas percepções de brechas e violações, e, tendo conhecimento destes, torna-se possível aos gestores identificar possibilidades de melhora na gestão da relação de emprego contemporânea. Para tanto, a seguir, comenta-se sobre a gestão dos contratos psicológicos. 


\subsection{GESTÃO DOS CONTRATOS PSICOLÓGICOS}

Apesar de o contrato psicológico ser idiossincrático e sujeito a diversificados enviesamentos perceptivos, na opinião de Chambel (2013), há fatores que favorecem esta relação entre o indivíduo e a organização e ajudam a evitar casos de ruptura ou violação do contrato, tais como:

a)A comunicação frequente, por meio da qual se tem a oportunidade de aferir divergências e apresentar razões por eventuais mudanças que possam ter ocorrido em relação a promessas feitas; e,

b)A coerência entre as múltiplas fontes de informação, ou seja, entre os responsáveis pelo recrutamento, manuais de acolhimento, chefes, colegas e sistema de práticas de gestão de pessoas, com base nas quais os trabalhadores desenvolvem as suas percepções e interpretações sobre as obrigações mútuas.

Comunicações precisas e objetivas também são sugeridas por Siqueira e Gomide Júnior (2004, p.325). Uma das perspectivas de atuação dos profisssionais de gestão de pessoas é garantir um fluxo contínuo de comunicação, que possibilite a todos uma ininterrupta atualização das informações e decisões, decisões estas que devem ser tomadas com a participação dos empregados que sejam afetados por elas, conforme alertam Siqueira e Gomide Júnior (2004). De acordo com Cortês (2005), quanto mais eficaz for o processo de comunicação com os empregados, mais explícitos os contratos psicológicos serão. Além da quantidade de comunicação, também sua continuidade é de suma importância para reduzir níveis de violação dos contratos, à medida que as duas partes passam a visualizar sob uma ótica mais positiva a relação de troca.

$\mathrm{Na}$ medida em que se consegue um maior interesse dos empregados em buscar informações e em entender melhor a relação empregatícia, melhor sucedido será o contrato psicológico (VOS; BUYENS, 2004). Sobre o assunto, declaram Coyle-Shapiro e Parzefall (2005) que, mediante estudos realizados por Guest e Conway (2002) com 1306 diretores de gestão de pessoas, notou-se que uma comunicação esclarecedora já no recrutamento, bem como um nível eficaz de qualidade de comunicação pessoal e profissional estavam relacionadas a um contrato psicológico mais claro e com menos rupturas.

Ainda, Robinson e Morrison (2000) notaram, em sua pesquisa, que percepções de quebra de contrato eram menos prováveis de aparecer à medida que os empregados passavam por um processo de socialização estruturada e à medida que interagiam com os agentes organizacionais durante o recrutamento. Esta condição sugeriu que, tanto a socialização 
formal, quanto a comunicação no recrutamento podem reduzir o hiato entre a percepção dos empregados e dos agentes organizacionais no acordo de trabalho.

Robinson e Morrison (2000) também sugerem que os gestores devem ser mais cuidadosos em gerenciar as percepções dos indivíduos que já passaram por alguma experiência de quebra ou violação de contrato anteriormente. Pessoas que passaram por estas circunstâncias são especialmente mais propensas a perceber uma violação de seu contrato psicológico atual.

A confiança é fator preponderante na construção de um contrato psicológico bemsucedido, diz Cortês (2005), destacando-se que, segundo Robinson e Morrison (2000), ela se refere a expectativas ou crenças de um indivíduo de que outras ações, de outrem, serão benéficas, ou, ao menos, não serão prejudiciais para este indivíduo. Ao entrar em uma nova organização, por consequência, se o empregado tem confiança no empregador, o risco de uma quebra de contrato tende a ser menor.

Após a exposição do conteúdo teórico, que serve de fundamento para observar e interpretar o objeto de estudo desta pesquisa, a seguir, são descritos os procedimentos metodológicos escolhidos para o alcance dos seus objetivos.

\section{PROCEDIMENTOS METODOLÓGICOS}

Esta pesquisa se caracteriza como pesquisa aplicada, de abordagem predominantemente qualitativa, além de também se caracterizar como quantitativa. Esta pesquisa caracteriza-se como quantitativa, pois, trata de medir a opinião dos pesquisados (TAEs do CFH da UFSC) sobre fatores que afetam os contratos psicológicos em análise. Para tanto, utiliza-se de questionário misto, com questões fechadas que apresentam respostas dispostas em escala Likert, além de técnicas de análise estatística de dados, por meio da ferramenta de Excel, da Microsoft ${ }^{\circledR}$, e de tabelas de distribuição de frequência das respostas.

A pesquisa também se caracteriza como qualitativa visto que, de acordo com Richardson (1999), esta é aquela que ocorre à medida que se procura descrever a complexidade de determinado problema e a interação de variáveis, compreender processos dinâmicos vividos por grupos sociais, contribuir para um processo de mudança e permitir maior profundidade no entendimento das peculiaridades de comportamento das pessoas.

Quanto aos fins, a pesquisa classifica-se como descritiva. Já, quanto aos meios, tratase de um estudo de caso, pesquisa bibliográfica e pesquisa documental.Vergara (2013, p. 42) 
afirma que a pesquisa descritiva "expõe características de determinada população ou de determinado fenômeno", podendo“também estabelecer correlações entre variáveis e definir sua natureza". Já, o estudo de caso tem por propósito trazer uma descrição aprofundada sobre uma realidade determinada (YIN, 2005).

A pesquisa bibliográfica procedeu-se com levantamento da literatura sobre o tema, auxiliando na definição dos instrumentos de coleta de dados e na análise dos dados coletados. A investigação documental, neste caso, baseada em Leis, e Resoluções pertinentes, também é necessária para apoiar a fundamentação teórica e para elucidar considerações importantes sobre o tema.

\subsection{DELIMITAÇÃO DA PESQUISA: UNIVERSO E SUJEITOS DE PESQUISA}

A população da atual pesquisa é constituída pelos Técnicos-Administrativos em Educação (TAEs) do CFH da UFSC, ou seja, servidores públicos federais, de um dos onze Centros de Ensino do campus João David Ferreira Lima da UFSC, localizado em Florianópolis. O critério de acessibilidade foi determinante para definir a composição da população e amostra deste estudo, e, naturalmente, a unidade de estudo (CFH da UFSC).

São considerados, portanto, todos os TAEs do CFH que entraram na Instituição de 2008 a 2014 (no total de 28), constituindo-se, portanto, em um censo. Foram excluídos apenas os TAEs que estavam afastados por qualquer motivo ou que estavam em licença (no total de 4). Tais servidores que foram admitidos recentemente na Instituição (de 2008 a 2014), e, por isso, têm seus contratos psicológicos mais influenciáveis.

Conforme exposto na seção 3.2 (Classificação da pesquisa), este estudo leva em conta o uso da pesquisa bibliográfica, investigação documental, além de questionário, predominantemente fechado. Apresenta respostas a serem escolhidas, assim como também respostas a serem ponderadas em escala Likert, e apenas uma pergunta aberta.

O questionário para a coleta de dados está baseado nas dimensões delineadas por Maia e Bittencourt (2014), relativas ao Instrumento de Contrato Psicológico (ICP) validado em organização pública brasileira, o que motivou a sua escolha para esta pesquisa. Para o designdo questionário fizeram-se adaptações em relação ao conteúdo original do ICP (MAIA; BITTENCOURT, 2014), já que foram considerados, também, diversos outros fatores capazes de influenciar os contratos psicológicos, apresentado ao longo da Fundamentação Teórica deste estudo. 
Quanto às técnicas de análise dos dados obtidos, foi adotada a análise interpretativa, indicada por Triviños (1987).

E, para analisar os dados quantitativos, foi preciso fazer uso de ferramentas estatísticas para tabular as respostas, utilizando-se como ferramenta o aplicativo Excel, da Microsoft ${ }^{\circledR}$.

\section{APRESENTAÇÃO E ANÁLISE DOS DADOS COLETADOS}

\subsection{FATORES DE INFLUÊNCIA DOS CONTRATOS PSICOLÓGICOS}

No questionário aplicado para a coleta de dados, buscou-se levantar como se apresentam os fatores de influência dos contratos psicológicos, separando-os nas Dimensões Tangibilidade, Foco, e Escopo, trazidos por Maia e Bittencourt (2014). As perguntas foram elaboradas para medir, de acordo com a percepção de cada sujeito, o quanto as obrigações/expectativas, tanto dele para com o empregador, quanto do empregador para com ele, estão sendo atendidas.

Além disto, buscou-se identificar, dentre os fatores de influência apresentados, os que são considerados como de maior influência para os pesquisados, sejam eles relativos à dimensão Tangibilidade, Foco, e Escopo.

As questões relacionadas a fatores de influência nos contratos psicológicos relacionados à Dimensão Tangibilidade, buscam conhecer como se apresentam estes fatores, identificando em que nível a amostra concorda que ocorre cada um deles. Estas perguntas geraram os seguintes resultados, que podem ser visualizados na Tabela 01 - Apresentação dos fatores de influência relacionados à Dimensão Tangibilidade:

Tabela 01 Apresentação dos fatores de influência relacionados à Dimensão Tangibilidade.

\begin{tabular}{|c|c|c|c|c|c|}
\hline Questão & 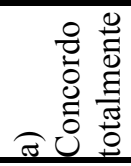 & 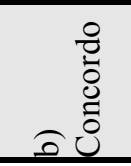 & 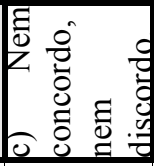 & 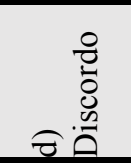 & 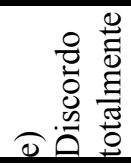 \\
\hline $\begin{array}{l}\text { Há clareza na comunicação das expectativas da sua } \\
\text { chefia imediata quanto ao seu trabalho. }\end{array}$ & $16,67 \%$ & $54,17 \%$ & $12,50 \%$ & $16,67 \%$ & \\
\hline $\begin{array}{l}\text { Há clareza na comunicação das suas expectativas } \\
\text { quanto à Instituição. }\end{array}$ & $4,17 \%$ & $62,50 \%$ & $20,83 \%$ & $12,50 \%$ & \\
\hline $\begin{array}{l}\text { A Instituição busca conhecer os desejos e planos de } \\
\text { carreiras dos seus servidores. }\end{array}$ & & $12,50 \%$ & $16,67 \%$ & $45,83 \%$ & $25,00 \%$ \\
\hline $\begin{array}{l}\text { Os critérios adotados na avaliação de desempenho na } \\
\text { UFSC são adequados. }\end{array}$ & & $8,33 \%$ & $37,50 \%$ & $33,33 \%$ & $20,83 \%$ \\
\hline $\begin{array}{l}\text { Suas atividades são compatíveis com sua } \\
\text { competência, ou características profissionais. }\end{array}$ & $12,50 \%$ & $41,67 \%$ & $25,00 \%$ & $16,67 \%$ & $4,17 \%$ \\
\hline São oferecidas capacitações pertinentes ao seu & $8,33 \%$ & $37,50 \%$ & $25,00 \%$ & $29,17 \%$ & \\
\hline
\end{tabular}




\begin{tabular}{|l|l|l|l|l|l|}
\hline $\begin{array}{l}\text { Você pretende se comprometer com a UFSC por um } \\
\text { longo tempo. }\end{array}$ & $20,83 \%$ & $37,50 \%$ & $25,00 \%$ & $12,50 \%$ & $4,17 \%$ \\
\hline Você busca melhoria de suas atividades. & $45,83 \%$ & $50,00 \%$ & & $4,17 \%$ & \\
\hline
\end{tabular}

Fonte: Dados primários (2016).

A partir desta Tabela, tecem-se alguns comentários importantes para análise dos dados, em relação à pesquisa bibliográfica e documental, como os que seguem.

Quanto à clareza na comunicação, os resultados sugerem atenção dos gestores à clareza na informação, diante da importância atribuída a este fator por autores, como CoyleShapiro e Parzefall (2005). Já que uma comunicação esclarecedora e de qualidade desde o ingresso na organização está relacionada a contratos psicológicos mais claros e com menos rupturas.

No que tange à busca, por parte da Instituição, em conhecer os desejos e planos de carreira, cabe aqui uma observação de que a progressão no plano de carreira está diretamente ligada a capacitações e incentivos à qualificação, e, consequente melhora na remuneração do Técnicos-Administrativo em Educação, no âmbito das Instituições Federais de Ensino, conforme Lei 11.091/05 (BRASIL, 2016). Portanto, a qualificação e capacitação são estimuladas pela Instituição e pelo Governo Federal, por meio de Lei Federal. Embora, nesta pesquisa, seja revelado o sentimento, por parte dos investigados, de que a Instituição tem falhado quanto a buscar conhecer mais os desejos e planos de carreira de seus servidores.

Para o fator avaliação de desempenho, tem-se que apenas 8,33\% dos sujeitos afirmaram que concordam que os critérios adotados na avaliação de desempenho na UFSC são adequados.O que significa que os critérios devem ser repensados pela Instituição.

No que se refere à compatibilidade de competências ou características profissionais, pode-se afirmar que há satisfação $(54,17 \%)$ em torno deste fator. Observando-se a opinião de Maia e Bittencourt (2014), depreende-se, desses resultados, que há uma tendência no alcance de um contrato equilibrado dos TAEs, do CFH da UFSC.

Quanto ao fator Capacitação, a grande maioria, que concorda que há ofertas de capacitações pertinentes ao seu trabalho, entrou na UFSC após 2012. Isto pode ter ocorrido devido ao fato de estar sendo mais divulgada a oferta dos cursos por meio de site específico da Instituição, atendendo a esta necessidade. Ao consultar a Coordenadoria de Capacitação de Pessoas (CCP) da UFSC, obteve-se a informação de que esta Coordenadoria surgiu no ano de 2010, e, logo após, também foi criado o Sistema Gestor de Capacitação (SGCA) que disponibiliza os cursos de capacitação disponíveis pela UFSC aos seus servidores; 
O fator comprometimento indicou que há intenção, por parte da maioria da amostra (58,33\%), em continuar se comprometendo com a Instituição, confirmando pressupostos analisados por Siqueira e Gomide Júnior (2004).

Com os resultados obtidos sobre a busca, por parte dos servidores, pela melhoria das atividades, pode-se inferir que a amostra busca, sim, a melhoria das atividades em seu trabalho $(95,83 \%)$.

Ao fim das questões referentes a esta Dimensão - Tangibilidade, perguntou-se Qual delas você considera ser a de maior influência em seu contrato psicológico atualmente? com o objetivo de identificar qual era considerada de maior influência em seu contrato psicológico. Portanto, os 3 fatores de maior influência, sob a percepção dos TAEs do CFH que ingressaram na UFSC de 2008 a 2014, para a dimensão tangibilidade, são:

a) $1^{\circ}$ - Compatibilidade de competências ou características profissionais (9 respostas);

b) $2^{\circ}$ - Clareza na comunicação das expectativas da chefia imediata quanto ao trabalho (5 respostas);

c) $3^{\circ}$ - Comprometimento (4 respostas);

As questões relacionadas a fatores de influência na Dimensão Foco buscam, identificar em que nível a amostra concorda que ocorre cada um deles.

Quanto ao fator de influência Expectativas, não se demonstrou ser este um fator que possa estar prejudicando os contratos psicológicos (29,17\% discordam e 41,67\% concordam).

O fator Relação de trocas merece atenção dos gestores $(51,84 \%$ discordam haver uma troca justa entre dedicação à UFSC e aquilo que se recebe em troca), pois, segundo Dulac (2005), afeta o processo de interpretação dos indivíduos que, se não for bem explicada pode trazer reações negativas e sentimentos de violação de contrato psicológico.

No que se refere à Confiança, fez-se uma pergunta semelhante à anterior, para conhecer se há confiança de que haverá uma troca justa, mas, desta vez, em relação à confiança de que será retribuído futuramente. Há, neste fator, certa criticidade, visto que $50 \%$ estão insatisfeitos, e, baseando-se em Levinson et al (1962), é a satisfação das expectativas de reciprocidade futura que motiva as duas partes do contrato a continuar na relação.

O fator Remuneração apresentou-se como um fator de muito descontentamento (para 66,67\%). Vale lembrar, novamente, que a Remuneração pode ser melhorada com capacitações para progressão no plano de carreira, e também com incentivos à qualificação, concedidos aos 
servidores que possuem certificado, diploma ou titulação que exceda a exigência de escolaridade exigida para ingressar no cargo que ocupa. (BRASIL, 2016).

Quanto a Prazos e carga de trabalho, pode-se considerar que este não é um fator que esteja afetando negativamente a maioria da amostra (66,67\% estão satisfeitos).

Em relação aos fatores comunicação e cooperação entre os colegas de trabalho, podese afirmar que não é um fator negativo no ambiente (91,66 estão satisfeitos).

Já em relação à Utilização da capacidade de trabalho/competências, este não chega a ser um fator tão crítico, mas merece atenção pelo resultado obtido $(16,67 \%$ estão insatisfeitos).

Para o fator Condições de trabalho, inerente ao aspecto estrutura proposto por Davidson (2002), no momento em que foi realizada a coleta de dados para a pesquisa, as condições de trabalho apresentavam-se adequadas para a maioria da amostra (54,16\%).

O Empenhamento apresentou-se como um fator bastante positivo na influência dos contratos psicológicos da amostra, sugerindo, com base em Rousseau (1989), que há percepção pelo indivíduo de que suas expectativas estão sendo atendidas, fazendo com que retribuam em conformidade com esta percepção (100\% se dizem empenhados).

Por último, quanto ao Zelo pelos valores, informações, bens e equipamentos da Instituição, percebe-se, a partir da concepção de Campoy, Castaing e Guerreiro (2005), que os resultados demonstram haver comprometimento por parte dos TAEs investigados (100\%).

Ao apresentar a questão Qual delas você considera ser a de maior influência em seu contrato psicológico, atualmente? - procurou-se identificar, das questões referentes à dimensão Foco, qual era considerada de maior influência em seu contrato psicológico, atualmente. Portanto, os 3 fatores de maior influência, sob a percepção dos TAEs do CFH que ingressaram na UFSC de 2008 a 2014, para a dimensão Foco, são os que seguem:

a) $1^{\circ}$ - Comunicação e cooperação com os colegas de trabalho (7 respostas);

b) $2^{\circ}$ - Remuneração (4 respostas);

c) $3^{\circ}$ - Relação de trocas; e Condições de trabalho (3 respostas).

d) $4^{\circ}$ - Confiança; Prazos e carga de trabalho; Utilização da capacidade de trabalho/competências; e Empenhamento.

As questões relacionadas a fatores de influência nos contratos psicológicos relacionados à Dimensão Escopo buscam conhecer em que nível a amostra concorda que ocorre cada um deles. 


\section{FATORES QUE AFETAM A GESTÃO DE CONTRATOS PSICOLÓGICOS NA UNIVERSIDADE \\ FEDERAL DE SANTA CATARINA - UFSC \\ DOI: http://dx.doi.org/10.5007/1983-4535.2016v9n3p315}

Tabela 02 Apresentação dos fatores de influência relacionados à Dimensão Escopo.

\begin{tabular}{|c|c|c|c|c|c|}
\hline Questão & 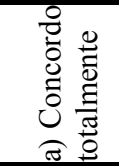 & $\begin{array}{l}0 \\
0 \\
0 \\
0 \\
0 \\
0 \\
0 \\
0\end{array}$ & 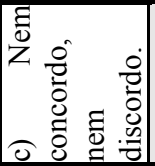 & 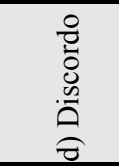 & 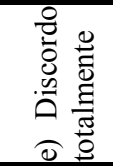 \\
\hline $\begin{array}{l}\text { Você considera ser reconhecido como pessoa pela Instituição, } \\
\text { e, assim, suas necessidades pessoais serem respeitadas. }\end{array}$ & $25,00 \%$ & $37,50 \%$ & $20,83 \%$ & $16,67 \%$ & \\
\hline $\begin{array}{l}\text { Você passou por algum processo de socialização ao entrar na } \\
\text { Instituicão. }\end{array}$ & & $25,00 \%$ & $12,50 \%$ & $45,83 \%$ & $16,67 \%$ \\
\hline $\begin{array}{l}\text { Você tem possibilidades de desenvolvimento pessoal e } \\
\text { profissional na Instituição. }\end{array}$ & $4,17 \%$ & $58,33 \%$ & $12,50 \%$ & $20,83 \%$ & $4,17 \%$ \\
\hline Você considera que seu trabalho é reconhecido. & $8,33 \%$ & $50,00 \%$ & $37,50 \%$ & $4,17 \%$ & \\
\hline $\begin{array}{l}\text { Você tem autonomia para realizar seu trabalho como achar } \\
\text { mais adequado. }\end{array}$ & $20,83 \%$ & $58,33 \%$ & $12,50 \%$ & $4,17 \%$ & $4,17 \%$ \\
\hline $\begin{array}{l}\text { Você tem liberdade de contribuir com suas opiniões e sua } \\
\text { criatividade. }\end{array}$ & $16,67 \%$ & $66,67 \%$ & $12,50 \%$ & $4,17 \%$ & \\
\hline $\begin{array}{l}\text { Você se preocupa com a Instituição e com o seu trabalho de } \\
\text { modo a trabalhar fora do horário de trabalho, se necessário. }\end{array}$ & $20,83 \%$ & $58,33 \%$ & $12,50 \%$ & $8,33 \%$ & \\
\hline Você aceitaria mudar de atividades/função, se necessário. & & $54,17 \%$ & $33,33 \%$ & $4,17 \%$ & $8,33 \%$ \\
\hline
\end{tabular}

Fonte: Dados primários (2016).

Pode-se observar que, em relação ao Reconhecimento, tanto no Reconhecimento pessoal quanto profissional, a maioria $(62,50 \%$ e $58,33 \%$, respectivamente) concorda que são bem atendidos.

Já quanto à Socialização, 62,5\% da amostra discorda, ou discorda totalmente, que tenham passado por algum processo de socialização. Com base em Robinson e Morrison (2000), uma socialização estruturada, além de uma boa comunicação com os agentes organizacionais desde a entrada na organização reduzem as possibilidades de quebra/ruptura de contrato, de modo que ajusta as expectativas de acordo com a realidade.

Em relação a Possibilidades de desenvolvimento pessoal e profissional, a maioria $(62,50 \%)$ concorda que são atendidas. Da mesma forma, também se encontram favoráveis os fatores Autonomia (79,16\%), Liberdade de contribuir com opiniões e criatividade $(83,34 \%)$, Preocupação com a Instituição e com seu trabalho (79,16\%), assim como também se encontra favorável o fato de concordarem em realizar Mudança de atividade/função, se necessário $(54,17 \%)$, o que permite ajustes de competências profissionais em alguns setores.

Ao perguntar Qual delas você considera ser a de maior influência em seu contrato psicológico, atualmente? Identificou-se que entre as questões apresentadas,os 3 fatores de maior influência sob a percepção dos TAEs do CFH que ingressaram na UFSC de 2008 a 2014, para a dimensão Escopo, são:

a) $1^{\mathrm{o}}$ - Possibilidades de desenvolvimento pessoal e profissional (6 respostas); 
b) $2^{\circ}$ - Reconhecimento do trabalho (5 respostas);

c) $3^{\mathrm{o}}$ - Reconhecimento como pessoa, com respeito às necessidades pessoais; e Autonomia (4 respostas, cada);

Apesar de se ter obtido resultados positivos, assinala-se que falhas percebidas nos fatores relacionados neste capítulo podem gerar rupturas dos contratos psicológicos ocasionando atitudes e comportamentos indesejáveis. Por isso, com base em Dulac (2005), é evidente a atenção que os gestores devem dispensar ao assunto. Compreender as variáveis, os fatores e os mecanismos que influenciam nestas percepções oferece aos gestores o suporte para identificar as possibilidades de melhoria. Sendo assim, apresentam-se alternativas de ação para a gestão destes contratos.

\subsection{ALTERNATIVAS DE AÇÃO PARA A GESTÃO DOS CONTRATOS PSICOLÓGICOS DO CFH/UFSC}

Como uma das propostas principais para uma gestão mais eficiente dos contratos psicológicos, propõe-se a criação de uma Comissão de acompanhamento no CFH. Para isso, os seus integrantes devem tanto se qualificar como gestores de contratos psicológicos, como, também, estudar os contratos psicológicos do público a ser gerido.

Além disso, para que todos fiquem mais à vontade, hierarquicamente, para expor seus problemas, suas percepções de brechas ou violações, ou suas insatisfações, sugere-se que estas Comissões sejam formadas por representantes da própria classe, ou seja, TAEs.

Ainda, sugere-se que a área de gestão de pessoas da UFSC colabore com ações de apoio, como:

a) Entrevistas para alocação do servidor nomeado de acordo com suas competências e características profissionais;

b) Acompanhamento da socialização do servidor desde o ingresso na instituição, para garantir sua melhor adaptação no ambiente de trabalho, comprometimento afetivo, e melhorar desvios relacionados a aspectos normativos, de modo que percebam a realidade de forma mais positiva, evitando possíveis rupturas ou violações em seus contratos psicológicos;

c) Oferta de mais oportunidades de capacitações e treinamentos para desenvolvimento pessoal e profissional;

d) Intermédio de comunicação com órgãos do governo federal responsáveis pela melhora no plano de cargos, carreira e salários, e/ou possibilidades de crescimento profissional por desempenho e mérito;

e) Realização de Avaliação de Desempenho, que identifique possíveis falhas impeditivas à potencialização de desenvolvimento pessoal e profissional, e analise a realidade organizacional onde o servidor esteja lotado. 
Ou seja, a área de gestão de pessoas pode contribuir efetivamente com a gestão dos contratos psicológicos nos aspectos mais objetivos, mais tangíveis, como os listados no parágrafo anterior, mesmo considerando as limitações impostas a uma organização pública federal. Porém, esta gestão não pode contar somente com este setor, que deve se destinar apenas como apoio à gestão dos contratos psicológicos. É necessário um acompanhamento mais próximo das pessoas, das situações vividas e dos diversos fatores que possam interferir no equilíbrio destes contratos, inclusive, para a compreensão e ajuda nas questões mais subjetivas e intangíveis, que envolvem o constructo. Desta forma, sugere-se que uma Comissão de acompanhamento em cada unidade da instituição possa, por meio de levantamentos periódicos feitos com instrumentos, como o ICP validado trazido por Maia e Bittencourt (2014). Além disso, ao se apresentar como canal de comunicação entre as partes dos contratos psicológicos, por meio da qual as pessoas podem reclamar suas insatisfações na busca por melhorias, as Comissões estariam, por si só, trazendo maior confiança no alcance das expectativas.

Um trabalho conjunto, integrando ações da Gestão de Pessoas e estas comissões podem ajudar, em muito, não somente a gestão dos contratos psicológicos, como manter uma eficiente sustentabilidade dos contratos psicológicos em equilíbrio.

Além da formação de Comissões para acompanhamento dos contratos psicológicos em cada Unidade da UFSC, servindo de canal de comunicação entre os diversos entes da instituição, também se propõe, como outra principal alternativa de ação, ainda para vencer o conformismo e atender à complexidade que envolve a gestão de pessoas no mundo atual, que se proceda a um trabalho de conscientização da importância da gestão dos contratos psicológicos e da necessidade de uma comunicação eficaz entre as partes da relação de trabalho.

Além disso, com base em Robinson e Morrison (2000), sugere-se aos gestores um maior cuidado com as percepções dos indivíduos que já passaram por alguma experiência de quebra ou violação de contrato anteriormente, pois estas são mais propensas a perceber uma violação de seu contrato psicológico atual.

Considerando-se que a Dimensão Tangibilidade, de Maia e Bittencourt (2014), referese ao nível de objetividade dos termos do contrato, à abertura e transparência por parte do empregado (TAE), e, por parte do empregador, à demonstração de que o servidor é parte da organização, e à clareza na definição das atribuições, oportunidades e recompensas, propõe-se 


\section{FATORES QUE AFETAM A GESTÃO DE CONTRATOS PSICOLÓGICOS NA UNIVERSIDADE \\ FEDERAL DE SANTA CATARINA - UFSC \\ DOI: http://dx.doi.org/10.5007/1983-4535.2016v9n3p315}

como alternativa de ação, para esta Dimensão, um trabalho de investigação constante sobre as necessidades pessoais e profissionais da amostra pesquisada.

Quanto a uma investigação constante sobre as necessidades pessoais e profissionais, cabe uma comunicação clara entre as partes. Conforme afirma Cortês, (2005), os contratos psicológicos serão mais explícitos quanto maior for o processo de comunicação, que também devem ser contínuos para reduzir os níveis de violação. Também conforme Coyle-Shapiro e Parzefall (2005), quanto maior a percepção de que as obrigações estão sendo cumpridas, maiores serão os esforços de reciprocidade, mesmo que antecipando suas obrigações, na confiança de serem recompensados.

Como alternativa de ação para a gestão da Dimensão Foco, no intuito de melhorar os fatores que não foram apresentados como favoráveis, e manter os que foram, propõe-se também aqui uma comunicação clara e frequente, desde a entrada do servidor na Instituição, para reduzir os hiatos entre as percepções destes e dos agentes organizacionais. Sugere-se adequado, assim como também sugerem Robinson e Morrison (2000), um gerenciamento de responsabilidades, além de explicações honestas e adequadas para cada situação. Assim, todos poderão ter claras suas responsabilidades/obrigações e o que verdadeiramente se pode esperar na relação de troca e, se algo não acorreu como esperado, explicações podem reduzir percepções de injustiça na relação, melhorando o fator confiança.

Quanto ao fator remuneração, como a amostra faz parte de um universo de servidores públicos federais, também se sugere, a exemplo do que foi trazido para a Dimensão Tangibilidade, intensificar o incentivo à qualificação e capacitação de seus servidores para que possam alcançar melhores níveis de remuneração.

É oferecida, como proposta de ação para a Dimensão Escopo, que se garanta, de forma mais ampla, o reconhecimento ao trabalho dos TAEs e a eles próprios, levando em consideração necessidades e características de cada indivíduo, de modo que se atinja uma relação de trocas cada vez mais benéfica para ambas as partes (Instituição e TAE). Aqui também caberia estudar a possibilidade de implantar meios que assegurem a meritocracia, como proposto por Schikmann (2010).

Mesmo que em uma instituição, como a UFSC, que se caracteriza como uma universidade de caráter público federal, também é possível sugerir, alicerçando-se em Grillo (1996), a adoção de incentivos como proposta de ação, pois estes proporcionam motivação, e são considerados, pelo autor, como meio mais adequado para estimular o desempenho das 
funções e reduzir a acomodação. Podem-se incentivar os servidores, proporcionando-lhes, por exemplo, licenças para qualificações e capacitações quando solicitadas e, até mesmo, o estímulo ao aperfeiçoamento profissional, com vistas a alguma espécie de reconhecimento com a funcionalidade de incentivo.

Com esta análise, depreende-se que um processo de comunicação clara e constante é base para a gestão dos contratos psicológicos dos TAEs do CFH/UFSC. Para isso, ficam como principais propostas eleger e capacitar uma Comissão de acompanhamento com competência necessária para a gestão dos contratos psicológicos, além de realizar um trabalho de conscientização quanto à necessidade de gestão destes contratos e de uma comunicação eficaz para que os contratos psicológicos de cada indivíduo se tornem mais explícitos, gerando benefícios para as partes envolvidas na relação, e evitando que consequências indesejadas venham a ocorrer.

\section{CONCLUSÃO}

Por meio deste trabalho, foi possível se realizar um estudo sobre contratos psicológicos firmados no CFH/UFSC por seus servidores, e, sobretudo, constatar a necessidade de que tais contratos sejam permanentemente geridos.

Optou-se por realizar este trabalho considerando a figura de empregador em seu sentido amplo, pois compreende que os contratos psicológicos estão sujeitos a influência de diversos fatores envolvidos. Portanto, ao se analisar o empregador em sentido mais amplo, podem ser considerados, além da chefia imediata, a Direção da Unidade, também a Secretaria de Gestão de Pessoas - SEGESP, a UFSC, e, ainda, o Governo, com suas Leis e Decretos.

O levantamento realizado sobre os fatores de influência dos contratos psicológicos dos TAEs do CFH da UFSC que ingressaram nesta Instituição entre 2008 e 2014 proporcionou informações sobre o grau de concordância na ocorrência dos fatores de influência, para cada uma das Dimensões (Tangibilidade, Foco e Escopo), além de identificar quais os fatores foram considerados pela amostra como de maior influência, atualmente, em seus contratos psicológicos.

No que se refere à Dimensão Tangibilidade, o fator eleito como de maior influência refere-se à Compatibilidade de competências ou características profissionais. E, por último, estão a busca, por parte da Instituição, em conhecer os desejos e planos de carreiras dos seus servidores e a busca, por parte dos servidores, pela melhoria das atividades. Foi detectado 
que, com exceção desses dois últimos fatores, que tem menor capacidade de influenciar os contratos, na opinião dos pesquisados, para os demais não há muito descontentamento, visto que a maioria concordou que estes fatores estão sendo atendidos. Para esta dimensão, foi verificado que os gestores devem voltar sua atenção a conhecer os desejos e planos de carreira destes TAEs e manter neles a busca por melhorias de suas atividades. Portanto, como propostas de ação, sugere-se a realização de um trabalho de investigação constante, por meio de uma comunicação clara entre as partes, das necessidades pessoais e profissionais desta amostra. Também foi sugerida a realização da revisão de planos de cargos, carreira e salários com base na meritocracia, além de se intensificar o incentivo e autorização de licenças para capacitações e qualificações, assim como maior disponibilização de informações a respeito.

Na Dimensão Foco, o fator eleito como de maior influência é relativo à Comunicação e cooperação com os colegas de trabalho. Depreende-se, dos resultados obtidos para esta dimensão, que os fatores de influência estão favorecendo a gestão dos contratos psicológicos dos TAEs, do CFH da UFSC, com destaque ao aspecto comunicação e cooperação entre os colegas de trabalho. No entanto, é preciso dar especial atenção ao fator remuneração, em que, de acordo com a percepção da amostra, não está adequada às suas funções. Outro fator crítico é a relação de troca, pois apenas 09 (nove) sujeitos concordam que há justiça na relação de troca com a Instituição. Estar atento a esta percepção de injustiça na relação de troca é muito importante, pois quando o equilíbrio na relação não é percebido, é provável que ocorram ajustes cognitivos de compensação que podem chegar à vontade do servidor de abandonar a Instituição.

Também para a Dimensão Foco, propõe-se a comunicação clara e frequente, desde o ingresso do TAE na UFSC, para reduzir os hiatos que ocorrem entre as percepções e expectativas dele para com a Instituição. Já, quanto à remuneração, como a amostra depende de iniciativas do Governo Federal, uma das ações propostas é buscar incentivar a qualificação e capacitação de seus servidores para melhoria na remuneração.

No tocante à Dimensão Escopo, o fator de influência que prevalece é relativo à possibilidade de desenvolvimento pessoal e profissional. Para esta Dimensão, os fatores de influência também se apresentam de forma favorável. Embora a maioria da amostra concorde que há reconhecimento pessoal e profissional, e que, ainda, uma parcela considerável não concorda que este reconhecimento ocorra. 
A socialização, por sua vez, também merece atenção. Como já exposto, uma socialização e uma comunicação eficaz desde o ingresso da pessoa na organização permitem ajuste de expectativas, reduzindo as chances de ruptura ou violação do contrato psicológico.

Dentre todas as alternativas de ações levantadas, por meio da literatura, ou por meio da apresentação e da análise dos dados, destaca-se que esta pesquisa torna evidente a importância da comunicação clara e constante como base para qualquer ação.

Ainda, como propostas de ação para a gestão dos contratos psicológicos no $\mathrm{CFH}$, sugere-se um trabalho de conscientização da importância da gestão dos contratos psicológicos e da necessidade de uma boa comunicação entre as partes da relação profissional, e a formação de uma Comissão, composta, principalmente, por TAEs, para que todos os servidores tenham mais abertura para exporem suas insatisfações. Esta comissão deve fazer um intermédio entre os TAEs de seu Centro de Ensino e os gestores (em seu sentido amplo), devendo ser selecionada por suas competências (conhecimentos, habilidades e atitudes), mas, também, ser qualificada para aplicar as sugestões já feitas. Deverá analisar os contratos psicológicos do Centro, suas características, fatores de influências e prováveis reações, ou seja, ter sempre um diagnóstico atualizado dos contratos geridos, seja por um instrumento de coleta destas informações, ou mesmo como canal de comunicação entre as partes envolvidas, e, ao conhecer suas necessidades, desejos, motivações, e descontentamentos, possa ajudar com possíveis soluções, tanto as já sugeridas quanto outras que venham a identificar.

Visto que grande parcela da amostra apresentou insatisfação no trabalho e tendência para a vontade de sair da Instituição ou para pedido de remoção, este canal de comunicação pode ajudar no sentido de fornecer o conhecimento dos descontentamentos e agir de modo a melhorar suas expectativas.

Cabe, também na Conclusão deste estudo, que Gestão de Pessoas da Instituição tem seu importante papel de apoio para agir conjuntamente com estas comissões.

\section{REFERÊNCIAS}

BRASIL. Lei 11.091, de 12 de janeiro de 2005. Dispõe sobre a estruturação do Plano de Carreira dos Cargos Técnico-Administrativos em Educação, no âmbito das Instituições Federais de Ensino vinculadas ao Ministério da Educação, e dá outras providências. Diário Oficial [da] República Federativa do Brasil, DF, 12 jan. 2005. Disponível em: $<$ http://www.planalto.gov.br/ccivil 03/ ato2004-2006/2005/lei/111091.htm>. Acesso em: 05 jan. 2016. 
CAMPOY, Eric; CASTAING, Sébastien; GUERRERO, Sylvie. Abordagem metodológica do contrato psicológico: operacionalização, medida e análise de dados. In: DELOBBE, Nathalie, et al. Comportamento organizacional: contrato psicológico, emoções no trabalho, socialização organizacional. Lisboa: Instituto Piaget, 2005. v. 1.

CHAMBEL, Maria José. Contrato psicológico e comportamentos de cidadania organizacional. In: Psicologia organizacional: conceitos e práticas. 1. ed. Porto: Lidel, 2013. p. 119-140.

CORREIA, Rui; MAINARDES, Emerson Wagner. O desenvolvimento do contrato psicológico orientado para desempenhos de elevado rendimento. Psico, Potugal,v. 41, n. 2, p. 266-277, abr./jun. 2010.

CORTÊS, Leonardo Lopes da Silva. Aspectos que contribuem para a construção do contrato psicológico de indivíduos que ingressam em empresas do setor público. 2005. 100p. Dissertação (Mestrado Profissional em Administração) - Departamento de Administração, Pontifícia Universidade Católica do Rio de Janeiro, Rio de Janeiro, 2005.

COYLE-SHAPIRO, Jacqueline A. M; PARZEFALL, Mario Riitta.Explorar a teoria do contrato psicológico: questões-chave para compreender e investigar a relação de emprego. In: DELOBBE, Nathalieet al. Comportamento organizacional: contrato psicológico, emoções no trabalho, socialização organizacional. Lisboa: Instituto Piaget, 2005. v. 1.

DAVIDSON, $P$. The changing nature of the psychological contract in the it industry: 1997-2001. ReinoUnido: Kingston University, 2002. (Research Papers in Human Resource Management).

DULAC, Tanguy. Da formação à avaliação do contrato psicológico. In: DELOBBE, Nathalie et al. Comportamento organizacional: contrato psicológico, emoções no trabalho, socialização organizacional. Lisboa: Instituto Piaget, 2005. v. 1.

FOCHESATTO, Sidnei Alberto. Os planos de incentivos e recompensas como fatores de motivação: estudo de caso das duas maiores empresas do ramo metal-mecânico de Caxias do Sul. 2002. Dissertação (Mestrado em Administração) - Universidade Federal do Rio Grande Sul, Porto Alegre, 2002.

FRANÇA, Ana Cristina Limonge; RODRIGUES, Avelino Luiz. Stress e trabalho:uma abordagem psicossomática. 4. ed. São Paulo: Atlas, 2011.

GONDIM, Sônia Maria Guedes; SILVA, Narbal. Motivação no Trabalho. In: ZANELLI, Jose Carlos; BORGES-ANDRADE, Jairo Eduardo; BASTOS, AntonioVirgilio Bitencourt (Orgs). Psicologia, organizações e trabalho no Brasil. Porto Alegre (RS): ARTMED, 2004

GRILLO, AntonioNiccoló. Desenvolvimento de pessoal nas universidades. Santa Catarina: Insular, 1996.

GUEST, D.; CONWAY, N. Communicating the psychological contract: an employer perspective. Human Resource Management Journal, Malden, v. 12, p. 22-38, 2002. 
HERRIOT, P.; PEMBERTON, C. Facilitating new deals.Human Resource Management Journal, Malden, v. 7, n. 1, p. 45-56, jan. 2007.

LEVINSON, H. et al.Men, management and mental health. Boston, MA: Harvard University Press, 1962.

MAIA, Letícia Gomes; BITTENCOURT, Antônio Virgilio Bastos. Validação de instrumento de contrato psicológico. Avaliação Psicológica, São Paulo, v. 13, n. 3, p. 409-417, 2014.

MIGLIORINI, Mariceia Aparecida. A dimensão do contrato psicológico como acordo das expectativas do indivíduo nas relações de trabalho na organização. 2005. 145f. Tese (Doutorado) - Centro Tecnológico, Programa de Engenharia de Produção, Universidade Federal de Santa Catarina, Florianópolis, 2005.

MOTTA, Fernando C. P.; VASONCELLOS, Isabella F. G. Teoria geral da administração. São Paulo: Pioneira Thomson Learning, 2008.

RICHARDSON, Roberto Jarry. Pesquisa social: métodos e técnicas. 3. ed. São Paulo: Atlas, 1999.

RIOS, Mino Correia; GONDIM, Sônia Maria Guedes. Contrato psicológico de trabalho e a produção acadêmica no Brasil. Revista Psicologia: Organizações e Trabalho, Brasília, v. 10, n. 1, p. 23-36, jan./jun. 2010.

ROBINSON, S. L.; MORRISON, Elizabeth Wolfe. The development of psichological contract breach and violation: a longitudinal study. Journal of Organizational

Behavior.Malden, v. 21, p. 525-546, 2000.

ROBINSON, S. L.; ROUSSEAU, Denise.Violating the psychological contract: not the exception but the norm.Journal of Organizational Behaviour, Malden, v. 15, p. 245-259, 1994.

ROUSSEAU, Denise M. Psychological and implied contracts in organization.Employee Responsabilities and rights journal, [S.1.], v. 2, n. 2, 1989.

ROBINSON, S. L.; MORRISON, Elizabeth Wolfe. The development of psichological contract breach and violation: a longitudinal study. Journal of Organizational

Behavior.Malden, v. 21, p. 525-546, 2000.

SCHEIN, Edgar H. Psicologia organizacional. Tradução de José Luiz Meurer. Rio de Janeiro: Prentice-Hall do Brasil Ltda,1982.

SCHIKMANN, Rosane. Gestão estratégica de pessoas: bases para a concepção do curso de especialização em gestão de pessoas no setor público. In: CAMÕES, Marizaura Reis de Souza; PANTOJA, Maria Júlia; BERGUE, Sandro Trescastro. Gestão de pessoas:bases teóricas e experiências no setor público. Brasília, ENAP, 2010. 
SIQUEIRA, Mirlene Maria Matias; GOMIDE JÚNIOR, Sinésio. Vínculos do indivíduo com o trabalho e com a organização. In: ZANELLI, Jose Carlos; BORGES-ANDRADE, Jairo Eduardo; BASTOS, AntonioVirgilio Bitencourt (Orgs). Psicologia, organizações e trabalho no Brasil. Porto Alegre (RS): ARTMED, 2004.

SOUZA, Irineu Manoel de. Gestão das universidades federais brasileiras: uma abordagem fundamentada na gestão do conhecimento. 2009. 399 f. Tese (Doutorado) - Departamento de Engenharia de Produção, Universidade Federal de Santa Catarina, Florianópolis, 2009.

UFSC - UNIVERSIDADE FEDERAL DE SANTA CATARINA. Estrutura UFSC. 2015. Disponível em: $<$ http://estrutura.ufsc.br/>. Acesso em: 07 mar. 2015a.

. Centro de Filosofia e Ciências Humanas. 2015c. Disponível em:

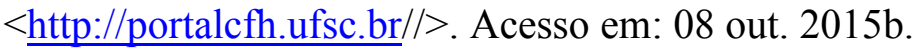

. Pró-Reitoria de Desenvolvimento e Gestão de Pessoas. 2016. Disponível em: http://prodegesp.ufsc.br/. Acesso em: 30 junho 2016.

VERGARA,Projetos e relatórios de pesquisa em administração. 14. ed. São Paulo: Atlas, 2013.

VOS, A.D.; BUYENS, D. Information seeking about the psychological contract: the impact on newcomers evaluations of their employment relationship. Belgica: Universiteit Gent, 2004. (FacultetEconomieEnBedrijfskunde, Universiteit Gent, Working Paper, n. 227).

YIN, Robert. Estudo de caso: planejamento e métodos. Porto Alegre: Bookman, 2005. 